\title{
FUZZY INFERENCE SISTEM MAMDANI UNTUK PENENTUAN KREDIT PADA KPN ESTIKA DEWATA
}

\section{Oleh}

\author{
I Made Budi Suwadnyana ${ }^{1}$, A.A. Gede Bagus Ariana ${ }^{2}$ \\ Program Studi Teknik Informatika \\ STMIK STIKOM INDONESIA \\ Email: balibudi55@yahoo.com ${ }^{1}$,gungariana@yahoo.com²
}

\begin{abstract}
ABSTRAK
Masalah penentuan kelayakan pemberian kredit merupakan masalah yang bersifat samar (fuzzy) dikarenakan menentuan tidak bisa ditentukan secara pasti layak atau tidak. Adapun parameter-parameter yang menjadi penentu keputusan pemberian kredit adalah gaji pemohon, nominal kredit dan jangka waktu pengembalian kredit. Penelitian ini mengambil studi kasus di KPN Estika Dewata yang merupakan badan usaha yang bergerak dalam usaha simpan pinjam di bawah naungan PT. Bank Mandiri (Persero) Tbk. Kanwil XI. Tahapan pemodelan diawali dengan proses fuzzyfikasi kemudian penghitungan fuzzy set, proses inferensi dan proses defuzzyfikasi. Variabel gaji pemohon dibagi menjadi gaji rendah, sedang dan tinggi, variabel kredit dibagi menjadi kredit rendah, sedang dan tinggi, variabel jangka waktu pengembalian dibagi menjadi jangka waktu pengembalian cepat, sedang, dan lambat. Proses inferensi menggunakan metode mamdani. Proses ter adalah defuzzyfikasi, dengan keluaran berupa nilai kelayakan kredit. Variabel kelayakan kredit dibagi menjadi tidak layak, layak dan sangat layak. Pembangunan pemodelan sistem menggunakan Matlab Fuzzy Toolbox. Uji coba pemodelan sistem dilakukan dengan menguji secara langsung proses pengajuan kredit di KPN Estika Dewata. Penelitian ini telah berhasil melakukan pemodelan fuzzy inference sistem metode mamdani untuk penentuan pemberian kredit.
\end{abstract}

Kata kunci: fuzzy inference system, mamdani, penentuan kredit

\section{Pendahuluan}

Seiring dengan berkembangnya perekonomian nasional, koperasi semakin mendapatkan tempat di hati masyarakat Indonesia. Fungsi utama Koperasi di Indonesia adalah sebagai tempat perhimpunan dana dari masyarakat. Koperasi sebagai salah satu lembaga simpan pinjam kepercayaan masyarakat terutama untuk pengusaha kecil perlu terus menjaga kepercayaan tersebut agar melaksanakan fungsinya sebagai tempat perhimpunan dana dan penyaluran kredit dengan baik.

Masalah kelayakan pemberian kredit cenderung bersifat samar (fuzzy), di mana untuk menentukan kelayakan tidak dapat ditentukan secara pasti layak atau tidak, contohnya suatu perusahaan bisa dikatakan $60 \%$ layak diberikan kredit. Hal 
tersebut dapat diaplikasikan dalam suatu sistem fuzzy yang disusun dari variabelvariabel yang didapat dari faktor-faktor yang mempengaruhi sistem fuzzy yang dibuat, dalam hal ini sistem untuk memprediksikan kelayakan suatu perusahaan untuk menerima kredit.

Koperasi Pegawai Negeri (KPN) Estika Dewata merupakan badan usaha yang bergerak dalam usaha simpan pinjam di bawah naungan PT Bank Mandiri (Persero)Tbk. Kanwil XI Denpasar, dimana anggota-anggotanya adalah pegawai tetap Bank Mandiri, pensiunan, pegawai outsoursing dan pegawai Koperasi yang berada di wilayah Denpasar.

Masalah yang sering terjadi dalam pemberian kredit yang terjadi di KPN Estika Dewata adalah proses pemberian kredit secara subjektif. Hal ini terjadi karena belum ada model dan aturan dalam penentuan kredit kepada karyawan. Pemberian kredit dilakukan atas dasar saling percaya dan saling kenal.

Berdasarkan alasan di atas maka akan dibuat suatu sistem inferensi sistem untuk memprediksikan kelayakan anggota diberikan pinjaman dengan cara menganalisa kemampuan gaji yang dimiliki, besarnya pengajuan kredit, dan jangka waktu pengembalian, yang nantinya dari hasil prediksi tersebut dapat di tarik kesimpulan apakah seseorang atau badan usaha tersebut telah dikatakan layak atau tidak diberikan pinjaman. Sistem ini akan diaplikasikan pada ToolBox Matlab.

\section{Tinjauan Pustaka}

\subsection{Kredit}

Pengertian kredit mempunyai dimensi yang beraneka ragam, dimulai dari kata kredit yang berasal dari bahasa latin "credo", yang berarti "saya percaya", yang merupakan kombinasi dari bahasa sansekerta "cred" (yang artinya "kepercayaan") dan bahasa latin "do" (yang artinya "saya tempatkan"). Pengertian kredit juga berasal dari kata "kredit" yang berasal dari bahasa Yunani "Credere" yang berarti "Kepercayaan" atau dalam bahasa latin "Creditum" yang berarti kepercayaan akan kebenaran. Ada beberapa pengertian yang diambil dari arti kata di atas antara lain :

Kredit adalah kemampuan untuk melaksanakan suatu pembelian atau mengadakan suatu pinjaman dengan suatu janji pembayarannya akan dilakukan dengan ditangguhkan pada suatu jangka waktu tertentu yang telah disepakati (IKAPI, 1988).

Sedangkan pengertian yang lebih mapan untuk kegiatan perbankan di Indonesia juga dirumuskan dalam bab I, pasal 1,2 undang-Undang Pokok Perbankan No. 14 Tahun 1967 yang merumuskan : "Kredit adalah penyediaan uang atau tagihan yang dapat disamakan dengan itu, berdasarkan persetujuan pinjam-meminjam antara bank dengan pihak lain dalam hal dimana peminjam berkewajiban melunasi hutangnya setelah jangka waktu tertentu dengan jumlah bunga yang telah ditentukan (IKAPI, 1988). 


\subsection{Teori Himpunan Fuzzy}

Teori himpunan fuzzy ini didasarkan pada logika (Kosko, B.1992). Terdapat nilai logika antara 0 dan 1 yang menyatakan tingkat kebenaran. Misalkan V adalah kumpulan objek yang secara umum dinyatakan dengan $\{\mathrm{v}\}$, yang berharga diskrit atau kontinyu. $\mathrm{V}$ disebut semesta pembicaraan (universe of discource), dan $\mathrm{v}$ mewakili elemen-elemenV. Suatu himpunan fuzzy A dalam semesta pembicaraan $\mathrm{V}$ dapat dinyatakan oleh suatu fungsi keanggotaan $\mu \mathrm{A}$ (membership function) yang mewakili nilai dalam interfal nilai logika $\{0,1\}$ untuk setiap $\mathrm{V}$ dalam $\mathrm{V}$ dan dinyatakan sebagai :

$$
\mu \mathrm{A}=\mathrm{V} \rightarrow[0,1]
$$

Himpunan fuzzy A dalam himpunan semesta $\mathrm{V}$ dapat dinyatakan sebagai pasangan antara elemen $\mathrm{v}$ dan tingkat fungsi keanggotaan, atau :

$$
\mathrm{A}=\{(\mathrm{v}, \mu \mathrm{A}(\mathrm{v})) / \mathrm{v} \quad \mathrm{V}\}
$$

Semua elemen $\mathrm{v}$ dalam $\mathrm{V}$ memberikan nilai $\mu \mathrm{A}>0$ disebut sebagai penyokong (support) dari himpunan fuzzy yang bersangkutan, jika $\mu \mathrm{A}=0.5$ maka $\mathrm{v}$ disebut sebagai titik silang (crosover) dan himpinan fuzzy dimana penyokongnya bernilai 1.0 disebut sebagai fuzzy tunggal (singleton).

\subsection{Fungsi Keanggotaan}

Pada proses perhitungan fuzzy yang terdapat pada aplikasi ini fungsi keanggotaan yang dipakai adalah fungsi keanggotaan trapesium. Kurva trapesium pada dasarnya memiliki bentuk seperti kurva segitiga, hanya saja ada beberapa titik yang memiliki nilai keanggotaan 1 seperti terlihat pada gambar 2.2. dan fungsi keanggotaannya dapat dirumuskan sebagai berikut (Kusumadewi, 2002):

$$
\mu[\mathrm{x}]\left\{\begin{array}{cl}
0 ; & \mathrm{x} \leq \mathrm{a} \text { atau } \mathrm{x} \geq \mathrm{d} \\
(\mathrm{x}-\mathrm{a}) /(\mathrm{b}-\mathrm{a}) ; & \mathrm{a} \leq \mathrm{x} \leq \mathrm{b} \\
1 ; & \mathrm{b} \leq \mathrm{x} \leq \mathrm{c} \\
(\mathrm{d}-\mathrm{x}) /(\mathrm{d}-\mathrm{c}) ; & \mathrm{c} \leq \mathrm{x} \leq \mathrm{d}
\end{array}\right.
$$

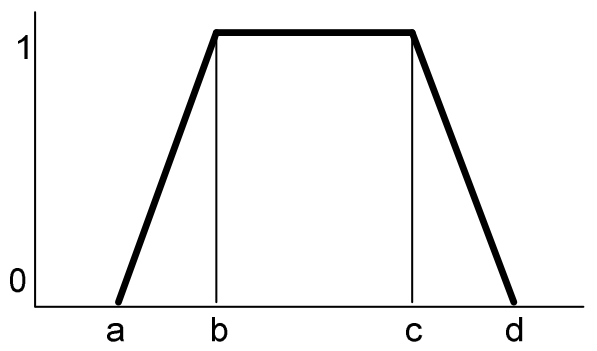

Gambar 1 Contoh Kurva Fungsi Keanggotaan Trapesium

\subsection{Sistem Inferensi Fuzzy}

Sistem Inferensi Fuzzy adalah sistem kerja komputer yang didasarkan pada konsep teori fuzzy, aturan fuzzy if-then, dan logika fuzzy. Pada aplikasi ini system inferensi fuzzy yang dipakai adalah model Mamdani. 
Model Mamdani sering juga dikenal dengan nama Metode Max-Min. Metode ini diperkenalkan oleh Ebrahim Mamdani pada tahun 1975. Untuk mendapatkan output, diperlukan 4 tahapan yang terdiri dari :

1. Fuzzyfikasi yang mentranformasikan masukan himpunan klasik (crisp) ke derajat tertentu yang sesuai dengan aturan besaran fungsi keanggotaan.

2. Aplikasi fungsi implikasi yang berisi aturan if-then.

3. Komposisi aturan.

4. Defuzzifikasi yang mentransformasi hasil fuzzy ke bentuk keluaran yang crisp.

\section{Metode Penelitian}

\subsection{Rancangan Umum Sistem}

Berikut merupakan gambaran umum sistem yang akan diteliti, proses pertama adalah input parameter-parameter yaitu gaji, kredit dan jangka waktu pengembalian. Setelah itu proses fuzzyfikasi untuk untuk mendapatkan nilai fuzzy masing-masing parameter, selanjutnya nilai-nilai fuzzy tersebut akan di-inferensi dengan metode fuzzy mamdani. Setelah proses inferensi dilakukan proses defuzzyfikasi untuk mendapatkan output dari sistem.

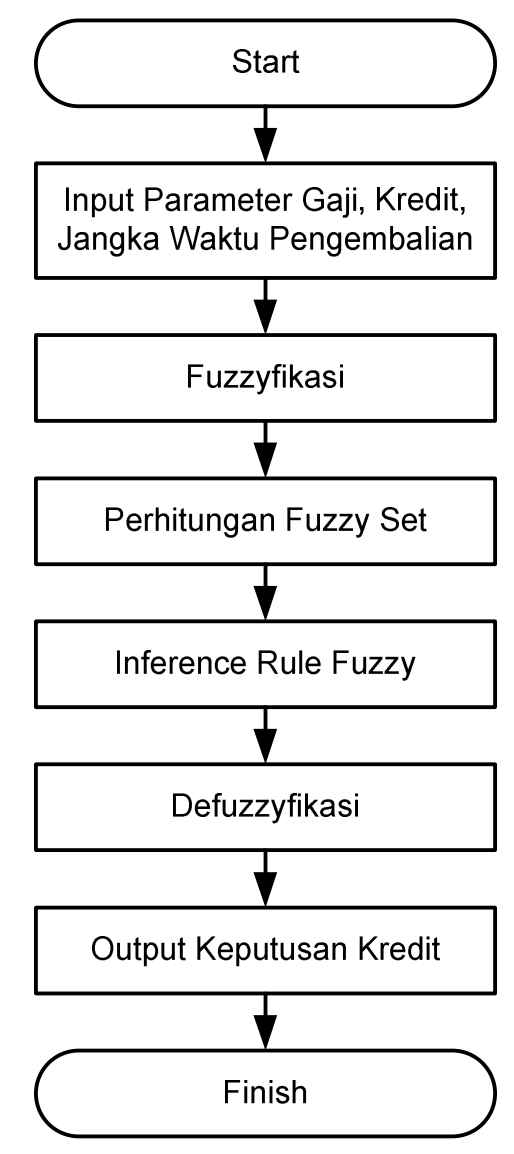

Gambar 2 Rancangan umum sistem penentuan kredit 


\subsection{Himpunan Fungsi Keanggotaan}

a. Total gaji, ada tiga kondisi (label) yang mewakili parameter ini yang antara lain meliputi : rendah, sedang, dan tinggi. Digambarkan sebagai berikut :

Tabel 1 Tabel total gaji

\begin{tabular}{ll}
\hline Label & Domain \\
\hline Rendah & $1.000 .000-2.500 .000$ \\
Sedang & $2.000 .000-4.000 .000$ \\
Tinggi & $3.000 .000-6.000 .000$ \\
\hline
\end{tabular}

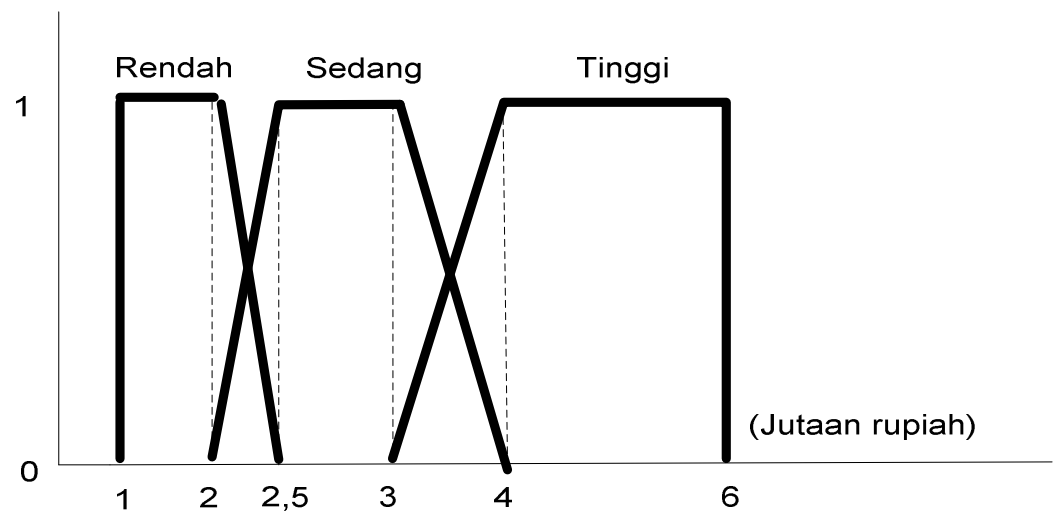

Gambar 3 Fungsi Keanggotaan total gaji

1. Himpunan fuzzy GRendah

$$
\mu_{\text {GRendah }}[\mathrm{g}]=\left\{\begin{array}{cc}
1, & 1 \leq g \leq 2 \\
(2,5-g) / 0,5 & 2 \leq g \leq 2,5 \\
0, & g \geq 2,5
\end{array}\right.
$$

2. Himpunan fuzzy GSedang

$$
\mu_{\text {GSedang }}[\mathrm{g}]=\left\{\begin{array}{cc}
0, & g \leq 2 \text { atau } g \geq 4 \\
(g-2) / 0,5 & 2 \leq g \leq 2,5 \\
1, & 2,5 \leq g \leq 3 \\
(4-g) / 1 & 3 \leq g \leq 4
\end{array}\right.
$$

3. Himpunan fuzzy GTinggi

$$
\mu_{\text {GTingi }}[\mathrm{g}]=\left\{\begin{array}{cc}
0, & g \leq 3 \\
(g-3) / 1 & 3 \leq g \leq 4 \\
1, & 4 \leq g \leq 6
\end{array}\right.
$$

b. Total pengajuan kredit, ada tiga kondisi (label) yang mewakili parameter ini yang antara lain meliputi : rendah, sedang, dan tinggi. Digambarkan sebagai berikut : 
Tabel 2 Tabel total pengajuan kredit

\begin{tabular}{ll}
\hline Label & Domain \\
\hline Rendah & $5.000 .000-20.000 .000$ \\
Sedang & $10.000 .000-50.000 .000$ \\
Tinggi & $40.000 .000-100.000 .000$ \\
\hline
\end{tabular}

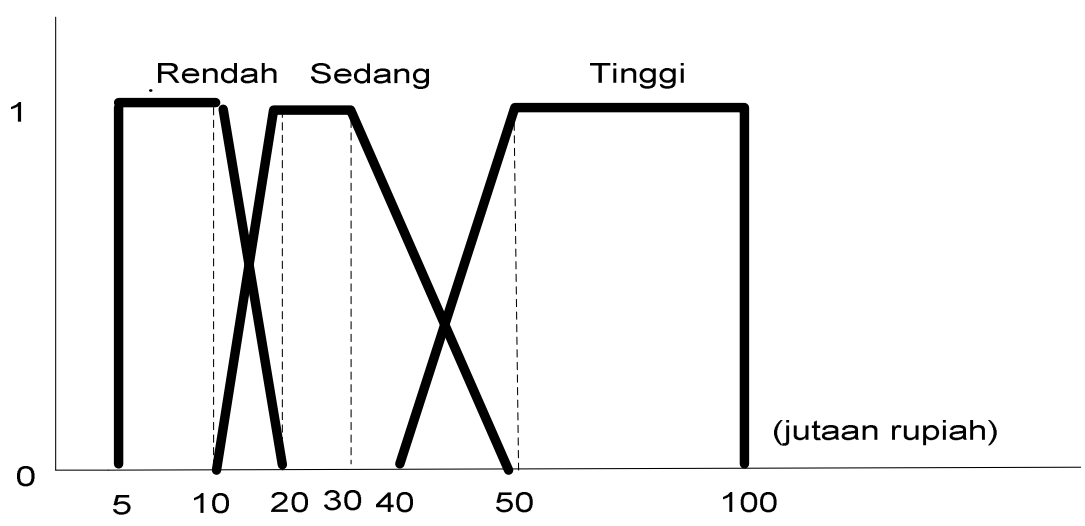

Gambar 4 Fungsi Keanggotaan total pengajuan kredit

1. Himpunan fuzzy KRendah

$$
\mu_{\text {KRendah }}[\mathrm{k}]=\left\{\begin{array}{cc}
1, & 5 \leq k \leq 10 \\
(20-k) / 10 & 10 \leq k \leq 20 \\
0, & k \geq 20
\end{array}\right.
$$

2. Himpunan fuzzy KSedang

$$
\mu_{\text {KSedang }}[\mathrm{k}]=\left\{\begin{array}{cc}
0, & k \leq 10 \text { atau } k \geq 20 \\
(k-10) / 10, & 10 \leq k \leq 20 \\
1, & 20 \leq k \leq 30 \\
(50-k) / 20, & 30 \leq k \leq 50
\end{array}\right.
$$

3. Himpunan fuzzy KTinggi

$$
\mu_{\mathrm{KTinggi}}[\mathrm{k}]=\left\{\begin{array}{cc}
0, & k \leq 40 \\
(k-40) / 10, & 40 \leq k \leq 50 \\
1, & 50 \leq k \leq 100
\end{array}\right.
$$

c. Jangka waktu pengembalian, ada tiga kondisi (label) yang mewakili parameter ini yang antara lain meliputi : cepat, sedang, dan lambat. Digambarkan sebagai berikut :

Tabel 3 Tabel total jangka waktu pengembalian

\begin{tabular}{ll}
\hline Label & Domain \\
\hline Cepat & $12-24$ \\
Sedang & $18-36$ \\
Lambat & $30-60$ \\
\hline
\end{tabular}




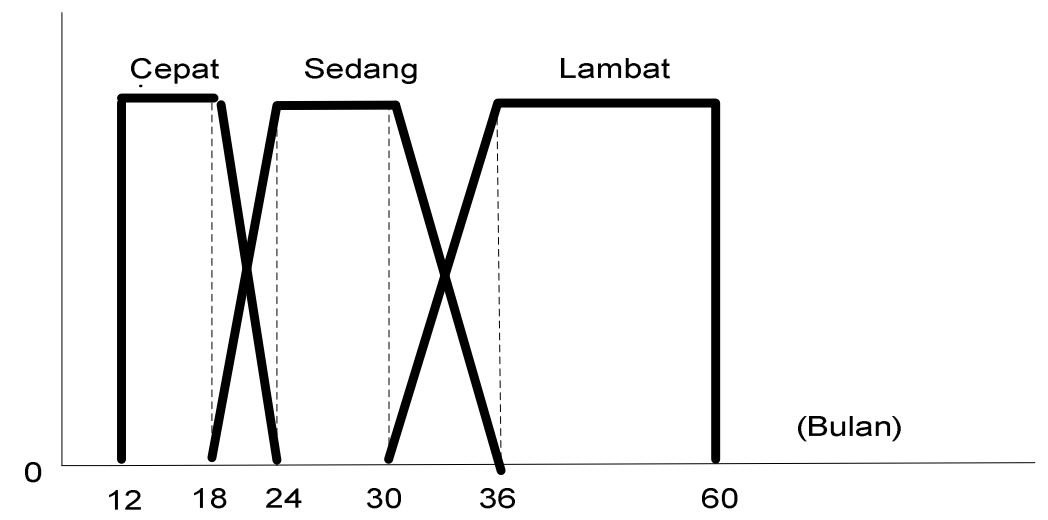

Gambar 5 Fungsi Keanggotaan jangka waktu pengembalian

1. Himpunan fuzzy JCepat

$$
\mu_{\text {JCepat }}[\mathrm{j}]=\left\{\begin{array}{cc}
1, & 12 \leq j \leq 18 \\
(24-j) / 6, & 18 \leq j \leq 24 \\
0, & j \geq 24
\end{array}\right.
$$

2. Himpunan fuzzy JSedang

$$
\mu_{\text {JSedang }}[\mathrm{j}]=\left\{\begin{array}{cc}
0, & j \leq 18 \text { atauj } \geq 36 \\
(j-18) / 6 & 18 \leq j \leq 24 \\
1, & 24 \leq j \leq 30 \\
(36-j) / 6 & 30 \leq j \leq 36
\end{array}\right.
$$

3. Himpunan fuzzy JLambat

$$
\mu_{\text {JLambat }}[\mathrm{j}]=\left\{\begin{array}{cc}
0, & j \leq 30 \\
(j-30) / 6 & 30 \leq j \leq 36 \\
1, & 36 \leq j \leq 60
\end{array}\right.
$$

d. Keputusan, ada tiga kondisi (label) yang mewakili parameter output ini yang antara lain meliputi : tidak layak, layak, dan sangat layak. Digambarkan sebagai berikut :

Tabel 4 Tabel keputusan

\begin{tabular}{ll}
\hline Label & Domain \\
\hline Tidak Layak & $0-40$ \\
Layak & $20-80$ \\
Sangat Layak & $60-100$ \\
\hline
\end{tabular}




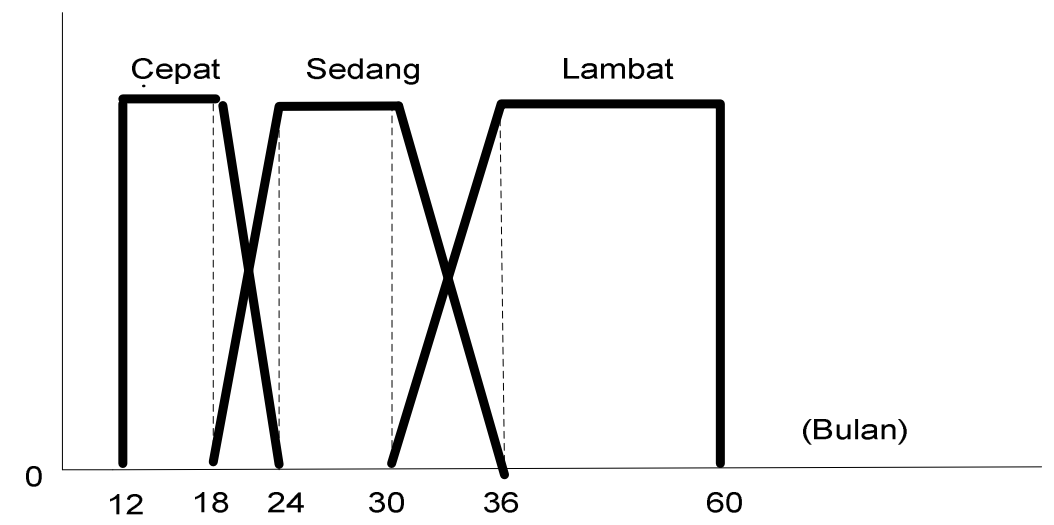

Gambar 6 Fungsi Keanggotaan keputusan

1. Himpunan fuzzy PTidakLayak

$$
\mu_{\text {PTidakLayak }}[\mathrm{p}]=\left\{\begin{array}{cc}
1, & 0 \leq p \leq 20 \\
(40-p) / 20, & 20 \leq p \leq 40 \\
0, & p \geq 40
\end{array}\right.
$$

2. Himpunan fuzzy PLayak

$$
\mu_{\text {PLayak }}[\mathrm{p}]=\left\{\begin{array}{cc}
0, & p \leq 20 \text { atau } p \geq 80 \\
(p-20) / 20 & 20 \leq p \leq 40 \\
1, & 40 \leq p \leq 60 \\
(80-p) / 20 & 60 \leq p \leq 80
\end{array}\right.
$$

3. Himpunan fuzzy PSangatLayak

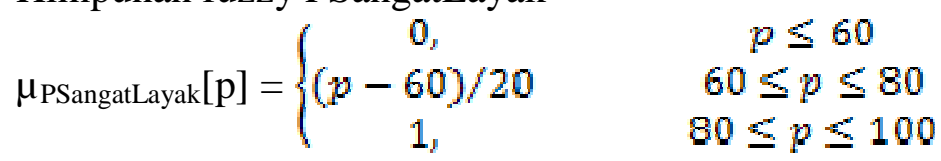

\subsection{Aturan Inferensi}

Berikut adalah aturan-aturan inferensi yang digunakan dalam pemodelan penentuan kredit. Aturan umum yang digunakan adalah:

IF GGaji AND KKredit AND JPengembalian THEN PKeputusan

Tabel 5 Aturan Inferensi

\begin{tabular}{lllll}
\hline Id rule & GGaji & \multicolumn{2}{c}{ Kariabel Input } & \multicolumn{1}{c}{ Keputusan } \\
R1 & GRendah & KRendah & JPengembalian & PKeputusan \\
R2 & GRendah & KRendah & JLambat & PLayak \\
R3 & GRendah & KRendah & JSedang & PLayak \\
R4 & GRendah & KSedang & JCepat & PLayak \\
R5 & GRendah & KSedang & JLambat & PTidakLayak \\
R6 & GRendah & KSedang & JSedang & PTidakLayak \\
R7 & GRendah & KTinggi & JCepat & PTidakLayak \\
\hline
\end{tabular}




\begin{tabular}{lllll}
\hline R8 & GRendah & KTinggi & JLambat & PLayak \\
R9 & GRendah & KTinggi & JSedang & PLayak \\
R10 & GSedang & KRendah & JCepat & PLayak \\
R11 & GSedang & KRendah & JLambat & PLayak \\
R12 & GSedang & KRendah & JSedang & PLayak \\
R13 & GSedang & KSedang & JCepat & PLayak \\
R14 & GSedang & KSedang & JLambat & PLayak \\
R15 & GSedang & KSedang & JSedang & PLayak \\
R16 & GSedang & KTinggi & JCepat & PTidakLayak \\
R17 & GSedang & KTinggi & JLambat & PTidakLayak \\
R18 & GSedang & KTinggi & JSedang & PTidakLayak \\
R19 & GTinggi & KRendah & JCepat & PSangatLayak \\
R20 & GTinggi & KRendah & JLambat & PLayak \\
R21 & GTinggi & KRendah & JSedang & PLayak \\
R22 & GTinggi & KSedang & JCepat & PLayak \\
R23 & GTinggi & KSedang & JLambat & PLayak \\
R24 & GTinggi & KSedang & JSedang & PLayak \\
R25 & GTinggi & KTinggi & JCepat & PLayak \\
R26 & GTinggi & KTinggi & JLambat & PLayak \\
R27 & GTinggi & KTinggi & JSedang & PLayak \\
\hline
\end{tabular}

\subsection{Proses Defuzzifikasi}

Metode defuzzifikasi yang digunakan adalah metode Centroid (Jang, J-S-R, Sun, C.-T \& Mizutani,E. 1996) menggunakan rumus sebagai berikut :

$$
\begin{gathered}
\int_{z} \mu A(z) z d z \\
\int_{z} \mu A(z) z d z
\end{gathered}
$$

\section{Hasil dan Pembahasan}

Pada uji coba sistem ini bertujuan untuk melakukan validasi perhitungan fuzzy untuk SPK Pemberian Kredit yang menggunakan Matlab. Beberapa test case yang dibuat antara lain sebagai berikut:
A. Contoh Kasus II
Total Gaji
$=2$ Juta
Total Pengajuan Kredit
$=40$ Juta
Jangka Waktu Pengembalian = 23 Bulan 


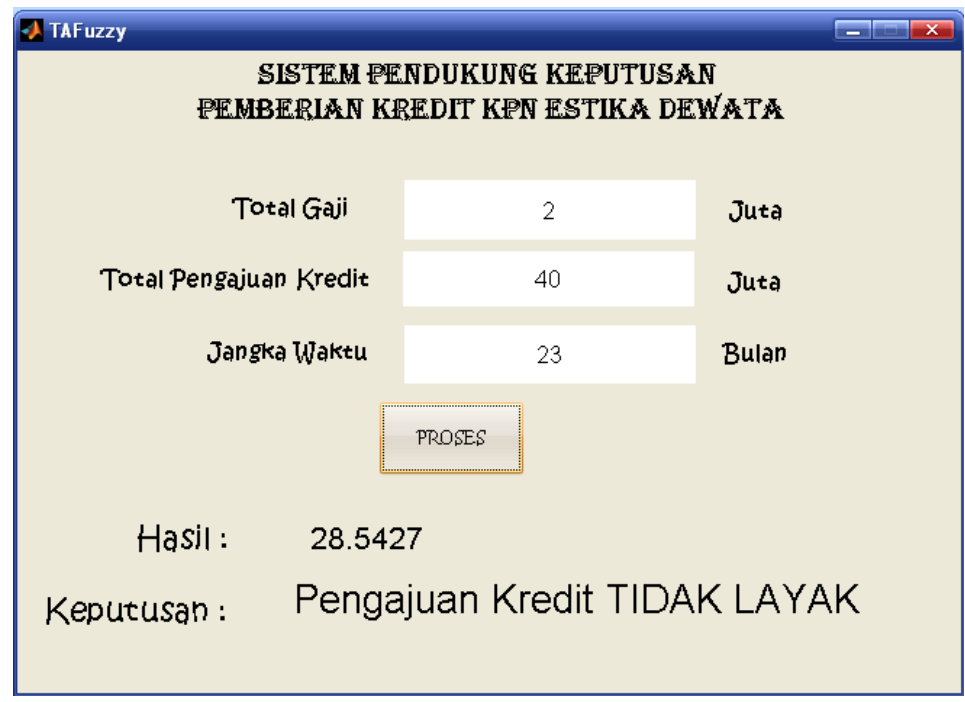

Gambar 7 Hasil keputusan kasus II

B. Contoh Kasus III

$\begin{array}{ll}\text { Total Gaji } & =4 \text { Juta } \\ \text { Total Pengajuan Kredit } & =10 \text { Juta } \\ \text { Jangka Waktu Pengembalian } & =15 \text { Bulan }\end{array}$

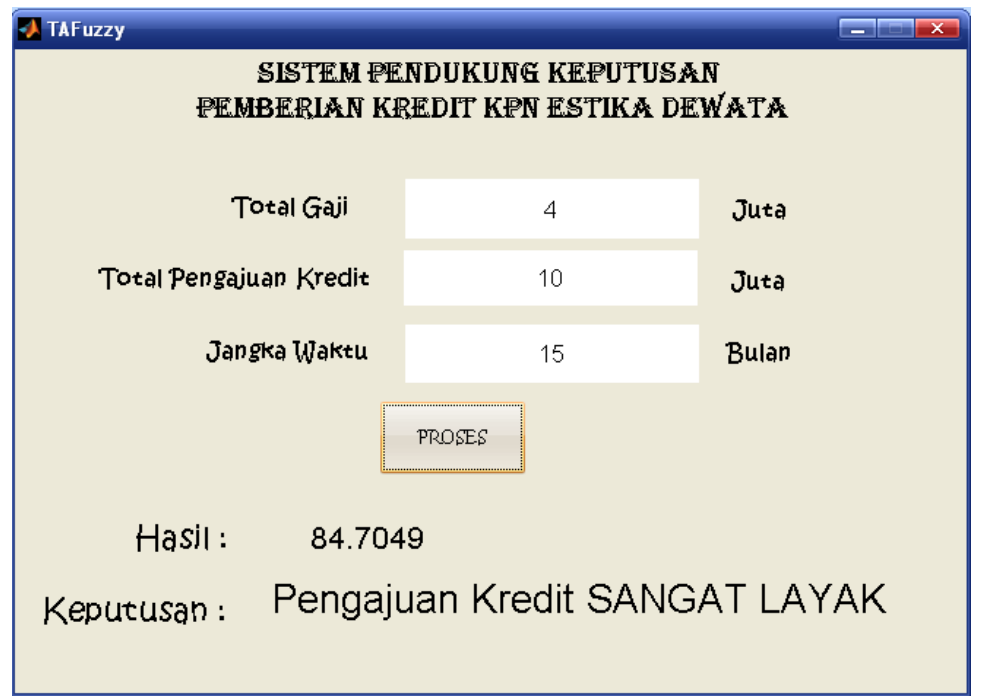

Gambar 10 Hasil keputusan kasus III

\section{Simpulan dan Saran}

\subsection{Simpulan}

Setelah melakukan perancangan dan pembuatan sistem pendukung keputusan pemberian kredit pada KPN Estika Dewata, dapat diambil beberapa kesimpulan, yaitu:

1. Sistem yang dibuat dapat digunakan untuk membantu pengambilan keputusan dalam pemberian kredit pada KPN Estika Dewata. 
2. Dari hasil percobaan dengan perangkat lunak MATLAB dengan toolbox logika fuzzy dalam penerapan terhadap masalah pemberian kredit, logika fuzzy dapat memberikan hasil yang lebih baik dan lebih mudah dibandingkan dengan perhitungan secara manual.

\subsection{Saran}

Untuk pengembangan Penelitian ini lebih lanjut, antara lain:

1. Supaya konsep logika fuzzy dapat berhasil diterapkan dengan baik, maka harus diperhatikan dalam penentuian range domain variabel yang optimal dan himpunan fuzzy.

2. Hasil keputusan akan lebih baik apabila faktor-faktor penentu dalam pengambilan keputusan ini lebih banyak dan menyertakan faktor-faktor pendukung lainnya.

\section{Daftar Pustaka}

Anggota IKAPI, 1988, Dasar-dasar Perkreditan, PT. Gramedia, Jakarta

Blair, Betty, 1994, Interview with Lofti Zadeh creator of fuzzy. by Betty Blair, URL:www.acer.com/aiweb/categories/magazine/24 folder/24 articles/24 fuzzylogic.html

Kusumadewi Sri, Purnomo Hadi, 2004, Aplikasi Logika Fuzzy untuk Pendukung Keputusan, Graha Ilmu, Yogyakarta

Kusumadewi Sri, 2002, Analisis dan Desain Sistem Fuzzy Menggunakan Tool Box Matlab, Graha Ilmu, Yogyakarta

Kusumadewi Sri, 2003, Artificial Intellegenci (Teknik dan Aplikasinya), Graha Ilmu, Yogyakarta 